\title{
Introducción a Concolorcorvo y a su itinerario de Buenos Aires a Lima *
}

\author{
Por Marcel Bataillón
}

\begin{abstract}
Reproducimos por su gran interés para la historiografía literaria americana y peruana, el presente estudio del notable erudito francés, que constituirá el prólogo de la traducción francesa del Lazarillo de Ciegos Caminantes, de Mme. Cottier, para la Colección de Obras Representativas que edita la Unesco.
\end{abstract}

El Lazarillo de ciegos caminantes no tiene nada de común con Lazarillo de Tormes, aparte el nombre que el malicioso héroo ha legado a la profesión con que comenzó sus aventuras y desventuras. El guía de ciego es aqui el "guía de bisoños viajeros" de Buenos Aires a Lima. Se trata de un itinerario.

El libro apareció en Lima a principios de 1776 con una falsa indicación de lugar y fecha: Gijón, 1773. A pesar de haber sido incluido por $\mathrm{O}$. Rich, en 1835, en la bibliografía americana, no conocería su primera reimpresión hasta 1908, por la Junta de His-

* El presente estudio no hubiera podido ser escrito sin el precioso concurso de D. José de la Peña, Director del Archivo General de Indias, de Sevilla, quien me ha enviado copias de importantes documentos inéditos (A. G. I. Lima 860 y Lima 993); en particular una cartar de Carrió al Rey (Madrid, 6 julio 1770). Desgraciadamente, ha sido imposible hallar la Relación de los méritos y servicios de Don Alonso Carrió y Lavandera, (impresa en Madrid el 13 de mayo de 1769), catalogada por J. T. Medina bajo el No 4387, en el tomo V de su Biblioteca Hispano-Americana. Igualmente debo hacer constar mi agradecimiento al señor Paul Verdevoye que me envió de Buenos Aires copias o ejemplares de artículos que no se pueden encontrar en París. 
toria y Numismática Americana de Buenos Aires, con un prefacio de Leguizamón. No obstante, continuó siendo un libro raro. En 1938, Ventura García Calderón lo incluyó en su Biblioteca de Cultura Peruana, publicada en París. Desde entonces ha sido reimpreso tres veces. Dos de esta reimpresiones han visto la luz en colecciones populares castellanas.

Hoy, como resultado de las investigaciones que, desde hace medio siglo, nos han ido haciendo esta obra menos enigmática, la paternidad de este libro es irrevocablemente otorgada a aquel a quien buenos jueces, como F. Monjardín y R. Porras Barrenechea, consideraban ya como su solo y único autor: Don Alonso Carrió de la Vandera (o Bandera). Dejémosle, sin embargo, guardar el pintoresco apodo con que ha revestido al personaje mezclado a su mistificación. Los editores más recientes han retenido a Concolorcorvo como un seudónimo "sonoro y significativo".

Es muy digno de elogio el seguro instinto con el que argentínos y peruanos han distinguido esta obra como uno de los monumentos literarios representativos de su siglo XVIII colonial. $\mathrm{Pe}-$ ro ya es hora de privarle de su dudosa aureola de indigenismo, debida a la superchería de don Alonso. Este visitador de Correos no ha prestado ni su pluma ni su diario a don Calixto Bustamanto Carlos Inga, cuyo nombre ha puesto en el frontispicio de la primera edición clandestina del Itinerarlo. Es raro que una mistificación no alcance crédito, poco 91 mucho Esta ha cubierto ya su camino. Don Calixto, indio o mestizo de quien ignoramos la proporción de sangre real que corría por sus venas, no tiene ya ningún título con qué figurar en la historia literaria de Nuevo Mundo, ni tan siquiera como un pariente pobre del Inca Garcilaso de la Vega, auténtico fundador de la literatura peruana.

Nada sabemos de los orígenes familiares de D. Alonso Carrió de la Bandera. El nombre Carrió parece catalán. Un guerrillero de Manresa lo ilustró en el siglo pasado. Quizá valga la pena notar que un homónimo de D. Alonso hacía carrera en la diplomacia al mismo tiempo que nuestro autor la hacía "en las Indias". J. J. Rousseau conoció a este otro Carrió, secretario de embajada en Venecia, donde le adoptó por compañero de aventuras amorosas y de quien nos dice formó parte luego de la Embajada Española en París.

Don Alonso nació en Gijón hacia 1715. En tanto no se halle la relación detallada de sus servicios, habrá que contentarse con 
algunos pocos documentos y sobre todo con su Lazarillo para poder reconstruir a grandes rasgos su carrera americana. Llega a los veinte años de su edad a México, donde pasará dos lustros, ya en la capital, ya en las avanzadas de México colonial de entonces, en la Nueva Vizcaya (actuales Estados de Durango y Sonora). Carrió se traslada a Lima en 1746, a sus 31 años. Allí contrae matrimonio en 1750 y fija su residencia. Bajo el reinado de Fernando VI, entre 1750 y 1757, es nombrado corregidor por cinco años de la provincia de "Chilques y Masques", o sea, en el confín de las actuales provincias de Ayacucho y de Apurímac. Ejerce allí las funciones de lugarteniente del Capitón General, de Alcalde Mayor de Minas y de Subdelegado del Juzgado de Bienes de Difuntos, cargos éstos que desempeñó a la entera satisfacción del Virrey y de la Audiencia de Lima. En 1762-63 España se encontró en guerra contra Inglaterra y se previno la defensa del imperio contra posibles desembarcos. El nuevo virrey $D$. Manuel de Amat concibió la idea de crear en Lima un regimiento de caballería con nobles voluntarios. Don Alonso se alistó en él e hizo todos los gastos de caballos, armas y uniformes requeridos por este servicio de honor.

Con Carlos III el despotismo llustrado sube al trono. En 1767, el Rey decreta la expulsión de la Compañía de Jesús, cuyas Misiones constituyen en Sudamérica una potencia espiritual y económica sin precedentes, un Estado en el interior del Estado. Los religiosos han de ser conducidos a Europa, bien vigilados por cierto, pero no $\sin$ las debidas atenciones. Se les provee de la vestimenta adecuada para tan largo viaje que debe atravesar las regiones antárticas, mientras se prepara en el puerto del Callao el navío de guerra "El Peruano". En él van a embarcar 181 jesuítas del Perú y de Chile. Don Alonso Carrió se ofrece a ser el convoyante de los misioneros repatriados. El navio hace una escala de un mes en Valparaíso. Aquí se quedan en tierra algunos enfermos, pero otros religiosos debidamente equipados por los cuidados del Presidente de la Audlencia de Chile, son embarcados, con lo que el número total de deportados asciende a 200. Conocidas son las actividades intelectuales y de información sobre América realizadas en su exilio por esta singular emigración, entre la que se hallaban hombres como el P. Lacunza y el P. Juan Ignacio Molina, por no citar más que dos chilenos ilustres por sus escritos.

En 1768, tras haber entregado los jesultas a las autoridades de Cádiz, Carrió se traslada a la Corte para solicitar la recom- 
pensa de sus servicios. Su candidatura al puesto de corregidor de Arica fracasa, no obstante haber conseguido tres votos del Consejo. No tiene más suerte para la vacante de Huamanga. Cansado de ser presentado siempre en tercer lugar, decide imprimir su relación de servicios y distribuirla en las oficinas y los Consejos, además de hacerse recomendar por D. Manuel de Roda y Arrieta, el ministro de Gracia y Justicia que había preparado la expulsión de la Compañía de Jesús. Con este alto apoyo, Carrió renueva sus gestiones para obtener el corregimiento de Huarochirí al que acababa de aplicar infructuosamente sus empeños. Tiene ya 55 años y se siente amargo. Se queja de haber echado a perder su salud y abandonado su familia y sus intereses en balde. ¿Deberá regresar manivacío a sus lares y llevar en Lima, donde durante veinticuatro años ha sostenido un decoroso papel, una existencia abatida, sin que un empleo venga a testimoniar la estimación regia por sus servicios? No le queda ya sino reembarcar en octubre en "El Peruano", tres años después de haber dejado la tierra peruana.

Pero es unos meses más tarde, en enero de 1771, cuando parte de La Coruña a bordo del correo real "Tucumán" con los dos servidores que le han acompañado a Europa. El 11 de mayo, al filo de la medianoche, aborda las Indias Occidentales, en Montevideo. A todos los sacrificios de tronquilidad y económicos que ha debido consentir para hacerse convoyante de los jesuitas, se añade una últimardesgracia! el navioviosiflama" se ha perdido con la pequeña fortuna que Carrió repatriaba al Perú, cerca de 20,000 pesos. Una vez más, el 4 de junio, Don Alonso, invocando su edad que le impide "trabajar corporalmente", solicita su nombramiento a un puesto vacante de corregidor 0 a cualquier otro puesto "compatible con su talento". Esta última solicitación asombrará a los funcionarios de Madrid. "¿Carrió? ¿No había sido ya recomendado al Virrey del Perú?" "Hágase de nuevo" pues, o insístase si ya ha sido hecho...

A falta de un lucrativo corregimiento, Carrió había obtenido antes de su partida de España una nueva misión de confianza. Aunque no haga ninguna mención de ello en su memorial del 4 de junio de 1771, había sido encargado de inspeccionar las postas radicadas entre Buenos Aires y Lima. El 12 de enero de 1771, el marqués de Grimaldi le había nombrado Visitador de esta ruta postal. Se había previsto su embarque en La Coruña hacia me- 
diados de febrero en el barco correo del Monopolio de Correos, y notificado su designación al Virrey Amat, a quien se le recomendaba además para un empleo estable en Lima, tal como interventor o tesorero de Correos en el Perú, una vez llegado al término de su visita.

Esta misión se inscribe en una gran reorganización de las Comunicaciones terrestres y marítimas de la monarquía española, coyuntura ésta sobre la que el señor Walter B. L. Bose, erudito historiador de los Correos de Sudamérica, ha proyectado hace 19 años una nueva luz. ${ }^{2}$ Y esta circunstancia va a hacer de Carrió un escritor.

La reforma a la que el marqués de Grimaldi ha ligado su nombre contribuye al movimiento que, bajo los Borbones, acelera la concentración estatal de la potencia española. Los Reyes Católicos habían emprendido esta tarea desde el fin de la Reconquista. Isabel había recuperado para la Corona de Castilla las inmensas riquezas territoriales de las Ordenes Militares, revocando las concesiones hechas por sus predecesores a la caballería armada contra el infiel. El déspota ilustrado Carlos III incorpora a la Corona en 1768 el oficio de Correo Mayor de Indias que el viejo Fernando había concedido en 1514 a uno de sus consejeros, el doctor Lorenzo Galíndez de Carvajal y a sus descendientes. El título de este privilegio, "Correo Mayor de las Indias descubiertas y por descubrir" aecuerda fel título de "Almirante, Virrey y Gobernador de las Islas y Tierra Firme descubiertas y por descubrir" imprudentemente otorgado a Cristóbal Colón y a sus herederos. El último Correo Mayor hereditario había sido el conde de Castillejo, Don Fermín Francisco de Carvajal, heredero de un nombre que un ministro de Fernando VI había recientemente ilustrado por la organización de la Superintendencia de Correos y Postas. En lo sucesivo, esta administración será una Renta General, una de las fuentes de ingresos del Estado, como las Aduanas. Las Postas de Indias serían un sector de ella y no de los menos productivos.

La reforma de las Comunicaciones americanas había comenzado por la institución, en 1764 , de los correos marítimos cuyo puerto de base peninsular era La Coruña.

2 "El Lazarillo de ciegos caminantes y su problema histórico", en Labor de los Centros de Estudios, publicación de la Univ. Nac. de la Plata, Sección II, T. XXIV, año 1940, p. 219-287. La Plata. 1941. 
Aunque Don Alonso Carrió había sido encargado solamente de la inspección y de la reorganización de las postas terrestres de Buenos Aires a Lima, se sentía ya en misión a bordo del "Tucumán". Desgraciadamente, su Diario Náutico, si es que llegó a escribirlo, no ha llegado hasta nosotros. ${ }^{3}$ Sobre el cumplimiento de su misión, ejercida de total acuerdo con el primer Administrador general de Correos del Río de la Plata, Don Domingo de Basavilbaso, el señor Bose ha extraído de los Archivos Argentinos detalles muy interesantes. El trabajo de reorganización que se imponía en esta cabeza de línea de las postas sudamericanas fue ultimado en septiembre-octubre de 1771. A principios de noviembre, Don Alonso Carrió se pone en camino hacia Lima. El Lazarillo de ciegos caminantes es, en parte, la Relación de su visita y de las medidas adoptadas por el Visitador. Es la única Relación de este tipo conocida hasta hoy.

¿Qué razones le condujeron a hacer de ella una publicación clandestina? Este punto nos será mejor conocido cuando se haya estudiado detenidamente el voluminoso legajo del Archivo de Indias, del que el señor Bose anunciaba en 1941 el descubrimiento ( $\sin$ dar la referencia) y a cuyo estudio prometió entonces dedicarse. Pero como la cuestión no había avanzado un paso desde entonces, yo solicité en 1956 de un joven historiador francés, André Saint-LuBbuscara teste expediente en Sevilla. Lo encontró (A.G.I. Sección 8a. (Correos) Leg. 1162 yo, gentilmente, extrajo para mí los datos que me permitirán decir lo esencial sobre la aparición del misterioso libro. ${ }^{4}$

3 El único fragmento, cuya copia ha sido encontrada por el señor Real Diaz (véase Nota 4) es reproducido por él en facsímil [Nota de 1960].

4 Entregado a la UNESCO en junio de 1957 el original de estas páginas, recibí en octubre de 1958 de José J. Real Díaz un artículo que acababa de publicar en Sevilla sobre "Don Alonso Carrió de la Vandera, autor del Lazarillo de ciegos caminantes". en el tomo XIII del Anuario de Estudios Americanos con fecha 1956 (30 páginas y 2 láminas). El autor traza en este artículo la génesis y la historia del Lazarillo de Carrí y transcribe integralmente la carta de la que hemos extractado el pasaje esencial según la copia recibida del señor SaintLu en septiembre de 1956, y la reproduce en facsímil, así como un recibo autógrafo firmado por "Calixto Bustamante" en Potosí el 21 de agosto de 1772 . Este último documento atestigua que el "Inca" sirvió 
El comportamiento de D. Alonso Carrió en este asunto no pue. de ser comprendido sin tener en cuenta las diferencias que desde el principio de su misión le opusieron a su superior jerárquico de Lima, punto éste que también fue aclarado por el señor Bose en 1941. El rey había designado a D. José Antonio de Pando como "Administrador General de Correos del Virreinato del Perú" cuando la incorporación de este servicio a la Renta General de las Postas. Pando, partiendo de La Habana, había arribado al continente en Cartagena de Indias, puerta de la Nueva Granada al mar de las Antillas. La fase preliminar de su misión consistía en la inspección del sistema de los Correos terrestres entre este puerto y Lima. Pando la comenzó en 1769 y no la acabó hasta 1772, por haber sido largamente inmovilizado en Bogotá por una enfermedad.

Don Domingo de Basavilbaso trató desde un principio de ponerse en contacto epistolar con el nuevo Administrador general, pero sus esfuerzos fueron inútiles. Es probable que fueran las quejas de Don Domingo a este respecto lo que decidió al Gobierno de Madrid a designar otro inspector de los servicios postales entre Buenos Aires y Lima. La llegada de éste a Buenos Aires fue acogida por Don Domingo con gran alegría. Estos dos hombres estaban hechos para entenderse. Ambos tenían la misma concepción del servicio público y de los intereses reales a ellos confiados. Hombres de acción los dos se hicieron una misma y poco favorable idea de "Don Jose'", quien, segûn el "propio secretario del Virrey, se dejaba llevar por dos empleados de la Renta de Correos de Lima, a los que abandonaba el cuidado de las decisiones, no obstante disponer él de la inteligencia requerida para juzgar y decidir. Uno de los puntos en que Basavilbaso y Carrió $\because$

de escribiente a don Alonso durante diez meses de su viaje, con unos honorarios de 20 pesos por mes. Las cuentas de Don Alonso confirman que este "Don Calixto Bustamante Carlos Inga" entró a su servicio como escribiente en Mendoza y se separó de él en Potosí. Estos datos hacen ya casi inútil toda hipótesis sobre las razones de la superchería que consistió en presentar como extractado por este personaje el diario que él había escrito en parte al dictado de D. Alonso. El señor J. J. Real Díaz caba de reimprimir su estudio como introducción a la edición del Lazarillo de ciegos caminantes cuidada por Juan Pérez de Tudela (Biblioteca de Autores Españoles. t. CXXII: Relaciones históricoliterarias de la América Meridional, Madrid 1959, p. 245-277 [Nota de 1960]. 
manifestaron su desacuerdo con Pando era el relativo a la aplicación del nuevo sistema de percepción del porte de las cartas instituido por el gobierno. Las nuevas ordenanzas que prescribían el pago por el destinatario, aunque contaban con una larga tradición y ofrecian más garantías a la Hacienda real, invertían el uso establecido bajo el Correo Mayor de hacer pagar el porte al expedidor, tipo éste de percepción que aseguraba la retribución de los arrendatarios locales. Los consejeros de Pando, tal vez no muy desinteresados en este asunto le habían persuadido a mantener el antiguo sistema de percepción. En una carta dirigida a Carrió durante la estancia de éste en Potosí, Basavilbaso le puso al corriente de las medidas adoptadas por Pando, contrarias a las ordenanzas reales, asegurándole que, por lo que le tocaba, éstas serian acatadas en su jurisdicción. Bien informado, hablaba de "una guerra declarada" contra él y Carrió por el Administrador General de Lima.

Mientras el expediente Carrió no sea estudiado como merece, puede muy bien sospecharse que esta tensa situación se prolongó después de la llegada del Visitador a Lima. Ello debió influir en la concepción de su libro y en su modo anómalo de publicación. El Lazarillo está concebido como un itinerario útil a los viajeros, pero aparece sazonado de digresiones técnicas, de chanzas históricas y cuadros costumbristas, y presentado como extraído del diario de Carrió por un personaje irresponsable e ingenuo.

El libro fue impreso clandestinamente en $1775 \circ$ a principios de 1776 en una imprenta de Lima, seguramente la de los "Huérfanos". Para enmascarar esta infracción a las ordenanzas de imprenta, Don Alonso recurrió a una superchería, capaz quizá de engañar a lectores no avisados, pero no a las autoridades. Al pie del frontispicio inscribió el nombre de una imprenta imaglnaria que localizó en Gijón, su ciudad natal, al que añadió la fecha de 1773, difícilmente verosímil para la impresión en España de la Relación de un viaje a Lima acabado hacia la mitad de ese mismo año. Esta fecha debía dar a entender que el libro circulaba ya hacía varios años antes de su aparición en el Perú.

Pero Carrió no quería arrostrar complicaciones con sus jefes de Madrid. El 24 de abril de 1776 enviaba su libro a los Jueces Administradores generales de la Renta de Correos, con las explicaciones siguientes: 
Por est navío dirijo a Vuestras Señorías dos paquetes con 12 exemplares de mis Itinerarios, desde Montevideo a esta capital [Lima]... Las continuas ocupaciones en que me hallé hasta fin de el año 1774, no me dieron lugar a pensar en la impresión de mi viaje, hasta que los muchos amigos que tengo en la. Sierra me importunaron tanto por manuscritos, que sólo uno, que hice sacar, y con vastantes erratas, me tubo de costo 80 pesos, sin el papel, por lo que resolví hacer une impressión de 500 exemplares, para repartir a todos los Administradores Mayores de la Renta, desde Montevideo a Cartagena con sus travesías, y complacer a algunos amigos, reservando menos de la mitad, en que apenas sacaré el costo de papel, y enquadernación, sacrificando más de 400 pesos de mi corto caudal.

Disfracé mi nombre por no verme en la precisión de regalar todos los exemplares. No ignoran VSS. lo árido de un diario, particularmente en payses despoblados, por lo que me fué preciso vestirle al gusto del pays para que los caminantes se diviertan en las mansiones, y se les haga el camino menos rudo. Yo recelo, que no sean del agrado de VSS. por difuso y en algunas partes jocoso. Lo primero lo executé a pedimento de los tratantes en mulas, que no creo sea desgradable $\alpha$ ninguno, y aun pienso que ahí tendrán mucho la complacencia de saver a fondo la sustancia de este género de trajín.

En lo sgundo procedí según mi genio, en que no falté un punto a la reglidada. . . Letras

Estas explicaciones, incluso sf son sinceras, no encierran sin duda toda la verdad sobre esta publicación singular. ¿Por qué, habiendo resuelto disimular su personalidad oficial detrás de un "indio neto", que dice haberle acompañado y explotado su diario de inspección, no se limita Carrió a dotar a este fantoche del burlesco seudónimo de Concolorcorvo? ¿Por qué designarlo con el nombre de un indio de carne y hueso, cuando con ello le expone a persecuciones por infringir las ordenanzas de imprenta?

En 1929, el P. Vargas Ugarte ${ }^{5}$ reveló el nombre del tío de don Calixto, al qu éste hace alusión en nuestro libro. D. Juan de Bustamante Carlos Inga, gentilhombre de cámara de Su Majestad Fernando VI, era efectivamente miembro de una familia del Cuz-

5 "En pos del verdadero autor de El Lazarillo" en el Boletín del Instituto de Investigaciones Históricas, Año VII, Buenos Aires, eneromarzo de 1829. 
co descendiente de Cristóbal Paulo Topa Inga, el hijo de Huayna Capac que siguió a Almagro a Chile.

W. Bose dio más tarde a conocer una carta de recomendación en favor de don Calixto, dirigida en 1770 a Basavilbaso por un secretario del Virrey, Martín de Martiarena. Este presentaba a don Calixto como un joven de buenas prendas que, tras la muerte de su señor, un alto magistrado de Chile, se dirigía a Buenos Aires en busca de un clima que no fuera "contrario a su salud". Cosa curiosa, Basavilbaso y su hijo descubrieron que la firma de esta carla estaba "contrahecha" y así lo consignaron. ¿Lo comentarian bromeando con su amigo Carrió al año siguiente? ¿Sería ésta una de las razones del honor que le confirió el Visitador al ponerle en escena ( 0 en un brete) en su chistosa historia, y al llamarle "señor inca" con una condescendencia llana y amistosa?

De otra parte, Carrió, en su carta a los administradores de Madrid de la Renta General de Postas, insinuaba que se podría reeditar su libro bajo una forma más seria. Aligerado de sus digresiones, y ceñido a su objeto de guía de viajeros, el libro podía reducirse al cuarto de su contenido, y concediendo un igual número de páginas al "distrito de don José", es decir, a las rutas septentrionales inspeccionadas por Pando, se podrían imprimir por 600 pesos como máximo 1,000 ejemplares de un itinerario que $\alpha$ barcase las 2,000 leguas del frayectol Cartagena-Buenos 'Aires. ¿Quería Carrió manifestariasíl un celoeque el propio jefe de los servicios postales, menos inclinado a manejar la pluma, no había demostrado? Las raras alusiones del Lazarillo a los administradores generales parecen discretos zarpazos contra Pando. $Y$ es casi seguro que éste, consultado sobre la publicación proyectada por Carrió, no la hubiera aprobado.

Pero la cólera de Pando contra Carrió parece que fue provocada por otra memoria anónima y clandestina que salió en 1777 ó 1778 de la impenta de los Huérfanos de Lima. Este largo Manifiesto sobre "las utilidades que ha tenido el Rey de la incorporación de Correos a la Corona", del que el expediente Carrió contiene varias copias manuscritas, fue denunciado por Pando como un peligroso libelo. La edición, imputada a Carrió, fue confiscada. Se procedió a un registro en casa del autor y se levantó un inventario de sus bienes. Los impresores y el propio Carrió fueron detenidos. Tras muchas instancias, nuestro autor fue puesto en libertad, en atención a su edad y a su delicada salud, y pa- 
sado a la jubilación por el conde de Floridablanca. Ignoramos qué fue de él después de 1778.

¿Pierde el Lazarillo de ciegos caminantes su sabor e interés una vez descubierta su mistificación? Lejos de ello, ganará indudablemente siendo tratado ségún sus verdaderos méritos, que no son escasos.

No exageremos su valor artístico. Las gracias literarias con que ha sido adornado apresuradamente no deben obnubilarnos. Carrió, escritor por accidente, sentía suficiente respeto por la literatura como para juzgar su libro árido y mal escrito. Su cultura, como la de todos sus coetáneos de buena familia, era a base de humanidades. De ella había guardado el gusto por las ideas y las observaciones morales, con un pequeño bagaje de citas latinas. El Telémaco era el libro moderno que coronaba su cultura clásica. Sus lecturas españolas predilectas eran, con Don Quijote, "el ingenioso Gracian" y las poesías festivas de Quevedo. Es capaz de algunos accesos de humor picaresco, de algunas pullas contra el galicismo invasor, de algunos cuadros de costumbres un tanto rebuscados, como la descripción de las elegancias fastuosas y anticuadas del "gachupín" guatemalteco, o como el pasaje de los gauderios (antepasados de los gauchos del siglo siguiente). Todo esto deja pensar que si hubiera cultivado más sus dones habría sido, con Torres Villarroel y Cadalso, un sólido eslabón intermedio entre los moralistas picarescos del siglo XVII y los costumbristas del XXX. Puccinelli Converso"

El verdadero maestro al que él más se asemeja es Feijóo, el lúcido benedictino amante de las ciencias naturales, profesor de espíritu crítico y de alertada atención a las realidades. Si hay un pasaje de su libro que sitúa verdaderamente a Carrió es aquel en que - hacia el final del prólogo- se burla del "gran Peralta", lamentando que este peruano de peluca haya perdido su tiempo y su erudición en una literatura de glorificación del pasado (Lima fundada, España vindicada) en lugar de haber escrito la "historia civil y natural" del Perú. No sin irreverencia, le compara a un caballero rústico del Tucumán cuya biblioteca estaba compuesta de los Viajes anovelados de Ferñao Mendes Pinto por Extremo Oriente, de las Guerras civiles de Granada de Pérez de Hita, de una mitología antigua y de un librito popular sobre Carlomagno y sus doce pares; el buen hombre había asimilado estos cuatro libros a su propia substancia, pero ignoraba el nombre del 
predecesor del rey reinante y era incapaz de describir correctamente las siete u ocho leguas a que se limitaba su horizonte geográfico. Lo que a Carrió le interesa es lo real y lo actual, no lo libresco. La realidad americana más concreta es su objeto preferido. La conoce tanto en su conjunto como en el detalle y siempre por dentro y desde dentro. La forma misma con que hace suyas las consideraciones de Feijóo sobre los "españoles americanos" nos ayuda a precisar en qué sentido participaba él de una conciencia americana, no obstante situarse un poco al margen del mundo criollo. iMeras tonterías, lo que se dice entre los criollos acerca de la precocidad de sus espíritus y de su senilidad prematural Feijóo tiene razón cuando explica la diferencia de ritmo o de nivel intelectual entre la península y América por una diferencia de educación. Carrió sabe perfectamente cómo el suelo y el clima de Lima y México, sobre todo los de este último, pueden poner a prueba a los organismos. La tópica comparación entre los criollos y los españoles aclimatados en el Perú le parece injusta. "Aquí, dice, raro es el mozo blanco que no se aplique a las letras desde su tierna edad siendo muy raro el que viene de España con una escasa tintura a excepción de los empleados para las letras". Carríó se cuenta indudablemente entre la minoría llegada "con una escasa tintura". Pero, vuelto a Madrid, es ya un peruano, perulero, o sea, tanto como decir criollo; y encuentra natural que los madrileños le confundan "con los demás criollos". Pues es ya un español americanos Pero lo es con menos provincialismo que los peruleros nativos de Lima. Sus diez años de permanencia en México, cinco de los cuales en la capital, le permiten dominar la rivalidad entre las capitales de los dos virreinatos y elevarse a un juicio arbitral. A pesar de haber sido adoptado por Lima, no deja de reconocer que México está antmado de una vida más intensa, más ardiente por los estudios y las disputas, más en contacto con Europa, menos mezclado de negros y más rico de población indígena. A los que hayan oído la discordante sinfonía de claxon, de gritos y de organillos en las esquinas de la Tenochtitlán moderna no dejarán de llamar la atención las breves líneas en que Carrió concede ya a esta gran ciudad la palma del ruido y de la cultura escolástica: las fórmulas latinas vociferadas por los ergotistas trascienden no sólo de los colegios y de las oficinas sino también de las barberías, sin que logre dominarlas el tumulto de tantos coches, de tantos pregones de almanaques, folletos piadosos o golosinas. 
Es necesaria una edición anotada de este libro. La dificultad para el hispanista medio radica en parte en que el autor escribe en americano para los americanos. Carrió está perfectamente familiarizado con el vocabulario indígena que designa las cosas de la vida cuotidiana, y a veces desconcertantemente asimilado al vocabulario castellano; bajo su pluma, magno aparece designando una tintura roja y gato un mercado al aire libre, una especie de "rastro". Ambas palabras proceden de voces quichuas, maknu y katu. Pero, esto aparte, si la lectura de Carrió no es fácil, se debe tanto a los descuidos en que abunda su prosa como, sobre todo, al carácter técnico de numerosos pasajes. Emplea frecuentemente el vocabulario noble, un poco pedante, que el decoro impone a todo funcionario, pero, recurre aún más a la terminología de montes y caminos, de Correos o de la administración local. Sus nociones y opiniones de técnico las ha adquirido en calidad de corregidor e inspector de las rutas postales. Así, en largas digresiones, enriquece la geografía humana y la literatura político-económica americana de una época en que el conocimiento de las cosas concretas prevalece sobre las preocupaciones doctrinales o estilísticas.

Carrió se sentía muy satisfecho de su largo estudio sobre la cría, la doma y el comercio de las mulas. Incluso si lo ha insertado en su libro, como él mismo dice, por complacer a los tratantes en mulas del interior, debemos reconocerle el haber analizado con ello una actividad capital para Ámerica del sur. Los tratantes en mulas, su personal y sus recuas eran los principales usuarios de las rutas. Centrado en Córdoba y en Salta, su tráfico cubría un vasto espacio desde los pastizales argentinos hasta las regiones perdidas de la Sierra, hasta las ciudades mineras, hasta las capitales del Perú, suministrando a este inmenso país caballerías de carga, de silla y de tiro. Un cuadro así tenía para la época el mismo interés que tendría hoy el de la industria de automóviles y de su mercado interior en un continente recién abierto a la motorización. Carrió evaluaba en unas 500,000 el número de acémilas entradas en diez años en el territorio peruano (que comprendía Bolivia y el Ecuador). Y la mula tiene de análogo con la fabricación industrial que no se reproduce espontáneamente, siendo fruto de un cruce artifical e infecundo. Pero nuestro escritor no observa este tráfico en simple curioso o en economista desinteresado, sino que lo describe en hombre de negocios 
informado del lado financiero de las cosas. Las páginas consagradas a la remuneración de los convoyantes de mulas son obscuras. No se debe sólo a la familiaridad de Carrió con el antiguo sistema de calcular los porcentajes ( 40 por 100 significa en su lenguaje 40 sobre 140, y consecuentemente 100 por 100 significa 50 sobre 100), sino también a su identificación con una economía colonial muy apegada a la remuneración en especie, practicando los colonos, patronos y administradores reales el suministro forzoso de mercancías a los peones y a los indios. Sobre este sistema se basa aún, como es bien sabido, la forma actual más generalizada de la servidumbre en América del Sur, la servidumbre por deudas.

Carrió había sido corregidor y deseaba volver a serlo. El nos explica en dos palabras, como si fuera la cosa más natural del mundo, por qué los corregidores eran los principales y a veces los únicos compradores de mulas. Estas eran el principal artículo de los suministros forzosos o repartimientos que constituían el más seguro ingreso de estos funcionarios. Un tal Villalta, corregidor de Abancay, que se destacó como defensor del orden cuando la rebelión de Tupac Amaru, se hizo también famoso, hacia 1790, por su consumado arte de "repartir" las mulas a los caciques y a las comunidades indias: el comprador contra su voluntad encontraba la bestia atada a su puertat Una manera, entre otras, de imponer los beneficios de la civilización interesando en la difusión de ésta or sus difusores.

Este sistema de repartimientos de mercancías no coincidía a primera vista con los viejos repartimientos o encomiendas de indios a los primeros conquistadores sino por el nombre. De hecho, eran dos variantes de un mismo sistema colonial tendente a obligar a los indios al trabajo. Carrió, juez y parte en el asunto, parece hacer de buena fe la apología de los repartimientos de su tiempo: nos traza un cuadro idílico de los pueblos que no terminan nunca de pagar sus duedas al corregidor o más exactamente, que no llegan a liberarse de sus deudas hasta el momento en que cesa el corregidor en sus funciones al cabo de cinco años. Gracias a este sistema, estos pueblos son colmenas de trabajo en lugar de verse convertidos en hordas de víctimas de la ociosidad, entregadas a los piojos y a la embriaguez. El pueblo en plena actividad está dispuesto a acoger, con el nuevo corregidor, un nuevo repartimiento civilizador. Con la misma convicción defien- 
de Carrió el sistema de los obrajes, talleres de trabajo- forzado en los que los detenidos de derecho común y los prisioneros por deudas son convertidos en tejedores y mantenidos en condiciones de seguridad y de salubridad muy superiores a las de sus miserables alojamientos. Cuando nos habla del Potosí parece que va a escamotearnos el triste tema de la mita, esta ruda y obligatoria faena de las minas para la que frecuentemente se obligaba a poblaciones enteras a desplazarse, incluso de muy lejos, pero nos habla luego de ello a propósito de los confines de la provincia de Chucuito. En un croquis lleno de vida y sin patetismo ninguno, evoca esa especie de "feria divertida" en que los mitayos se despiden de sus parientes y amigos, unos riendo y otros llorando. Con sus mujeres e hijos, y empleando a las llamas y a los borriquitos como bestias de carga, se dirigen todos al Potosí, alimentándose en su largo recorrido del ganado que matan y de las papas que arrancan a la tierra. Estos "criados del Rey" viven sobre el país como una plaga de langostas o una tropa en país enemigo.

El colonialismo sin vacilación de nuestro Visitador se basa en una interpretación puramente colonial de la historia de América. Estamos con él en los antípodas del indigenismo. Carrió invoca a Solís sobre la conquista de México y a Herrera sobre la del Perú (aunque sus recuerdos acerca de ésta están un poco borrosos puesto que nos relata la historia de Atahualpa llamándole Manco Capac). -En balde se buscará en su Itinerario una sola página sobre las ruinas grandiosas del Perú prehispánico. Si nos habla de Tiahuanaco, es para darnos de este nombre una de esas etimologías indígenas y anecróticas a las que los criollos solían ser muy aficionados, y para refutar lo que Garcilaso dice de los chasquis o correos de los incas, no para maravillarse como aquél de los "grandes e increíbles edificios" que se ven aún. Los monumentos incaicos de El Cuzco no alertan su curiosidad. Concolorcorvo admite muy someramente que la antigua capital de los incas ha sido "muy mejorada por los españoles", y refuta la opinión según la cual hubieran debido transplantar la capital del alto país a una de las llanuras vecinas de El Cuzco. A este respecto, Carrió pone de relieve la ventaja que supuso el tener a mano, en el lugar mismo, la inmensa cantera de piedras ya labradas, que brindaba la ciudad india, y unos cimientos y muros que los españoles aprovecharon sin tener que demolerlos. So- 
bre la perfección del trabajo de estos muros que deja pasmados a los viajeros modernos él no nos dice una palabra. Es paradójicamente su pseudo-interlocutor indio el encargado de hacer la apología general de los conquistadores injustamente acusados por los religiosos del siglo XVI, cuyas "plumas ensangrentadas" suministraron una patética materia a los escritores antiespañoles de los dos siglos siguientes. No sólo los indios eran inhumanos y habian hecho numerosas matanzas de españoles, desde la de 1492 en que acabaron con los compañeros de Colón dejados por éste en la isla Española, sino que además eran incapaces de explotar sus riquezas mineras. Carrió remite a la leyenda los fabulosos tesoros de metales preciosos enterrados tras la muerte de Atahualpa: vieja decepción que durante mucho tiempo trabajó la imaginación de los criollos. Y afirma sin ambages que los españoles extrajeron en el Perú más metales preciosos en 10 años que los peruanos en 2,000 .

¿Es responsable la llegada de los conquistadores de una despoblación india? Carrió admite que las minas consumen un número importante de indios, que los españoles explotan las mejores tierras, que ellos mismos han creado por sus trabajos de irrigación, pero imputa a la deshonestidad de los caciques y de los auxiliares indígenas de la administración la responsabilidad de una buena partel del despojo que llevata los indios a la miseria y a la corrupción. Los delitos y las deudas a que esto da lugar conducen a los trabajos forzados y a la muerte prematura. $Y$, de otra parte, las mujeres indias, en el alto país glacial, no fueron nunca fecundas y el suelo no hubiera podido alimentar jamás a la inmensa población atribuida al Perú en el momento de la conquista. Se habla de 7 millones de peruanos empadronados bajo el virreinato de D. Francisco de Toledo (hacia 1572). Si se trata de cabezas de familia jhabría que evaluar la población indígena de entonces en más de 30 millones de almasl Pero en ninguna parte se han visto ruinas de aglomeraciones en proporción con la centésima parte de semejante multitud. Si se trata de 7 millones de almas solamente, esta cifra revela una extremada indigencia biológica si se la compara con la de España, país pobre y cuatro veces menos extenso, donde la población aumenta además muy poco. ¿Compensa la calidadlel menor vigor de la planta humana? La aptitud de los indios para los oficios artísticos, tan alabada por Las Casas en su Apologética Historia, no 
deslumbra a Carrió. No es que él la niegue. Antes "admite con su ironía un poco amarga, que se encontrará entre estos pueblos dóciles y pacientes veinte pintores por un herrero. Con mentalidad de colono, deplora que demasiados indios se sientan atraídos por las ciencias y otras vocaciones no manuales, cuando de lo que tiene precisamente necesidad el pueblo conquistador es de una mano de obra abundante. "Para los estudios - dice- los criollos bastan y sobran". Y en esta frase hay un dejo de inquietud ante este fenómeno observado por Feijóo: el afán de los criollos por hacer estudiar a sus hijos desde su más temprana edad para permitirles pretender las prebendas de la Iglesia y los empleos reales. Pero la idea de que los indios pudieran ser educados intelectual y socialmente al nivel de los criollos no se asoma a sus pensamientos.

A sus ojos, todo el porvenir de América está sustentado sobre los colonos más emprendedores y la administración pública. Vale la pena oírle citar a la orden del día de la América civilizada algunos nombres como el de un minero de Puno, su compatriota el magnánimo asturiano San Román, "gran hombre en su género". Cuando, ante las comarcas bárbaras del Chaco, que le recuerdan las avanzadas mexicanas de la Nueva Viscaya, imagina una política de repoblación capaz de reemplazar ventajosamente a la defensa militar, to cuando propone una inmigración de colonos flamencos o suizos, nos parece habérnoslas con un precursor de Sarmiento. En el dominio del urbanismo, 'Carrió se preocupa de la multiplicación de las cisternas en las ciudades desprovistas de agua como Oruro y La Plata. Una ciudad como Oruro, que a pesar de sus tesoros presenta una apariencia miserable, le. hace concebir un sistema de impuestos sobre la fundición de la plata, con los que financiar las obras públicas. Así, en todas sus ideas de progreso, se muestra ante todo como un técnico de la administración.

Es indudable que el antiguo convoyante de los jesuitas no les echa de menos. Sin que aboride el tema de frente, hace una observación significativa sobre esos pueblos de "misiones" que, entre tres o cuatro, podrían tal vez absorber un suministro de un millar de mulas si se privara a los corregidores del cuidado y beneficio del repartimiento. Su ingenio se carga de sal gorda cuando cita y da relieve al tratante en mulas Cosío, el montañés malsufrido, que hacía pastar su ganado en las tierras de los je- 
suitas y que, trabuco en las manos, amenazaba al buen Padre venido para expulsarle "con echarlo a la eternidad". Carrió parece hacerse de buena gana el intérprete de los rencores acumulados en dos siglos por los colonos laicos contra los colonizadores misioneros. Por más que él se guarde de querer combatir a los jesuitas exilados, no puede dejar de acusarles categóricamente de haber secuestrado durante ciento cincuenta años a los indios en sus misiones y de haberlos adoctrinado en lengua indígena,bajo el falaz pretexto que sus neófitos se corromperían al contacto con los españoles. Carrió insiste más bien en que los españoles descubrieron una América presa de abominaciones desconocidas en España: canibalismo, sacrificios humanos, idolatría, poligamia, incesto, sodomía, embriaguez... Un artículo esencial del programa de Carrió, que recuerda las ideas formuladas en 1550 por el Auditor Tomás López cuando su inspección de Centroamérica, es la organización de las "doctrinas" seculares en las que los indios aprenderían el castellano al tiempo que el catecismo, con lo que no podrían ya seguir invocando su ignorancia para sustraerse a las leyes. Nada de cristianización sin hispanización.

"Basta de indios", dice el Visitador a quien el tema importuna... ¿Se ha dado, pues, por interlocutor a este "Señor inca" solamente para lanzas ab indígena iletrado verdades desagradables? Se echa de ver que Carrió no quiere entablar un debate con un portavoz "de lo raza conquistada, puesto que hace de Concolorcorvo, supuesto indio pura sangre, un defensor de los conquistadores y un acusador de los indígenas. Por lo demás, no es imposible que Don Calixto Bustamante Carlos Inca, condenado a la notoriedad con tanta desenvoltura, fuese un indio paniaguado de los españoles y asimilado a su civilización. Carrió le ha prestado una actitud de aquiescencia benévola ante las tesis anti-indias del pueblo conquistador, en la que se puede ver todo un símbolo.

Más allá de este pseudo-diálogo, esgrima incruenta, el Visitador evoca más de un aspecto de la situación real de los indios sudamericanos quince años antes de la rebelión de Tupac Amaru. Ante todo, la segregación de hecho en que vive una importante masa indígena dispersada. A pesar de un esfuerzo único en el mundo para enseñar "la doctrina cristiana y los actos exteriores de la religión", tan sólo la población aglomerada en los pueblos 
es alcanzada por los doctrineros. Los indios bárbaros huyen al contacto de los que no hablan su lengua.

Sin embargo, no en todas partes donde el contacto existe se opera la fusión moral. Carrió caracteriza a los indios por el odio a los españoles y nostalgia del pasado prehispánico. Lejos de las aglomeraciones, reina entre las dos razas la ley del más fuerte o del más astuto. En los pueblos, donde todos deben someterse mal que bien a la ley, son los indios, dice Carrió, quienes, en contra de la opinión corriente, roban a los españoles. Los primeros son más astutos. Ahora bien, los indios deben el poco de civilización y de bienestar de que gozan a los españoles. Y éstos desearían ardientemente que los indígenas fuesen ricos para comerciar con ellos y enriquecerse con este comercio. Pero la feria de Cocharcas, donde se reúnen más de dos mil indios, es un espectáculo significativo: los autóctonos continúan haciendo entre ellos sus menudos intercambios inmemoriales, sin comprar un real de mercancía a los españoles. Estos hacen su propio tráfico entre ellos. Pero en los españoles se puede incluir, reconoce Carrió, a los mestizos y a otras "castas" mezcladas que se escalonan a niveles más o menos elevados, por encima de los indios no civilizados. Esta cuestión del mestizaje es la última sobre la que apreciaremos la lucidez sin hipocresía del Visitador. El ruega a su interlocutor juzgue B̈en español"za sus compatriotas autóctonos, sin perder de vista el "escepticismo general" de los indios que les lleva a dudar de todo, incluso de las verdades de la fe o de evidencias trilladas. Hele pues, a Concolorcorvo promovido a español y participando de las certidumbres de los conquistadores, él que desciende de los incas... "en línea tan recta como es el arco iris", él que se proclama indio puro "salvo las trampas de su madre" de las que él no sale por fiador... Pasémosle este rasgo algo descarado; Carrió, inventor literario de Concolorcorvó, se apoya en la tradición picaresca en la que es habitual que el po. bre diablo se exprese sin ninguna ilusión sobre la moralidad de sus progenitores. Nuestro autor es más serio al rehusar una frontera racial entre los pretendidos "indios netos" y los mestizos, entre los mestizos y los españoles. El indio puro, desde el momento que entra a servir en la casa de un español que le viste y le trata bien, se convierte socialmente en "cholo", como si tuviera sangre blanca en las venas. Todo depende de la manera de vida, parece insinuar Carrió, que asume serenamente la realidad del 
mestizaje, a sabiendas de que un mestizo puede recaer on la masa india bárbara o agregarse a la población civilizada según sea ignorado o reconocido por su padre español. ¿No es ésta, en definitiva, la significación sutil del desdoblamiento entre Carrió y el indio semi-real, semi-imaginario, al que ha admitido a dialogar con él?

Collège de France

Paris.

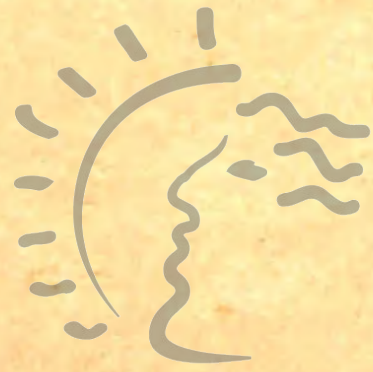

\section{Biblioteca de Letras}

